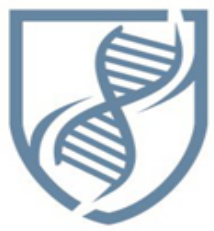

Journal of Bioscience and Applied Research
JBAAR

WWW.JBAAR.ORG

\title{
Ameliorative effect of olive leaves extract on hepatotoxicity and oxidative stress in streptozotocin-induced diabetic rats
}

\author{
Saber A. Sakr ${ }^{1}$, Karoline K. Abdel-Aziz ${ }^{2}$, Attalla F. El-kott ${ }^{2}$, Heba S. Khalifa ${ }^{2}$ \\ ${ }^{1}$ Zoology Dep. Faculty of Science, Menoufia University, Menoufia, Egypt \\ ${ }^{2}$ Zoology Dep. Faculty of Science, Damanhour University, Damanhour, Egypt
}

(Corresponding author email : sabsak@yahoo.com)

\begin{abstract}
Diabetes mellitus (DM) is a chronic metabolic disease. Olive leaves consists of phenolic compounds, flavonoids and volatile oil. The aim of this study was to evaluate the anti-diabetic and the curative effect of olive leaves extract on streptozotocin-induced diabetic rats. Forty male rats were divided into 4 groups, Group I; Animals were served as control. Group II; Animals were received oral Olive leaves extract (OLE) $0.5 \mathrm{mg} / \mathrm{kg}$ of body weight/day. Group III; Animals were injected intraperitoneally with a single dose of streptozotocin (STZ) (45mg $/ \mathrm{kg}$ of body weight) to induce diabetes. Group IV, Animals were received a single dose of streptozotocin and after 7 days received Olive leaves extract for four weeks. The results indicatet that injection of STZ provoked a significant increase $(\mathrm{P}<0.005)$ in serum ALT, AST and lipids. Moreover, Serum malondialdehyde was increased and the antioxidant enzymes SOD and CAT decreased. Histopathologically, the OLE group didn't show any histopathological changes. Diabetic animals showed many histopathological changes in liver e.g. destruction of liver architecture, congestion of blood vessels, Leucocytic infiltration, and cytoplasmic vacuolization of hepatocytes. The pancreas showed severe damages in the pancreas architecture and atrophy of $\beta$-cells. When animals treated with OLE, an improvement was observed in the biochemical parameters and liver and pancreas histology of these animals. It is concluded that OLE exhibited a pronounced hypoglycemic, hypolipidemic and ameliorative effects in diabetic rats

and this is may be attributed to the presence of its phenolic compounds.

Keywords: Diabetes, Olive leaves, Histopathology, liver rats, oxidative stress.

\section{Introduction}

The number of diabetes mellitus (DM) cases around the world is growing every year. More than 360 million people are predicted to be diagnosed as having diabetes by 2030 (Kim and Choi, 2009). Approximately 3 $5 \%$ of the current population of patients with DM is classified as having type 1 diabetes, and this number is still growing (Fu et al., 2011). Type $1 \mathrm{DM}$ is an autoimmune disease caused by $\mathrm{T}$ cell-mediated destruction of islet $\beta$ cells, leading to a disruption of insulin production (Cui et al., 2009). Moreover, $80 \%$ of the affected population lives in low- and middle-income countries, due to an increase in the inactive lifestyle, obesity and amount consumed of an energy-rich diet (Abo et al., 2008). Diabetes mellitus is a hyperglycemic disorder which causes overproduction of reactive oxygen species (ROS) and affects the brain, kidney, heart, liver, and other organs (Aggarwal and Harikumar, 2009). The two forms of Diabetes mellitus differ in their etiology. While type I Diabetes is mainly an autoimmune process, only the minority of type II Diabetes is based on an autoimmune process. The major immunological process is a destruction of pancreatic insulin-producing $\beta$-cell, which is caused not only by T-cell mediated cytotoxicity, but also by cytokine-induced cell death followed by the appearance of auto-antibodies
\end{abstract}


(Eizirik and Mandrup-Poulsen, 2001). Diabetic nephropathy is a major cause of morbidity in diabetic patients (Tesfaye and Selvarajah, 2012). Diabetic nephropathy is an earnest complication of diabetes mellitus. As the incidence of diabetes is growing worldwide, diabetic nephropathy has become the main cause of chronic renal disease in patients who need renal transplantation. It is also associated with an intensified risk of cardiovascular mortality and morbidity (Raptis and Viberti, 2000). Also, Oxidative stress has been reported as a key factor in the onset of pathogenesis and diabetic complications (Nakhjavani et al., 2013). Clinical and experimental studies proposed that the liver may influenced by DM in the longterm (Leclercq et al., 2007). Where, the liver being rich in mitochondria to perform metabolic functions is a crucially important organ and in a chronic hyperglycemic state, liver oxidative stress is considered as a relevant process (Ren et al., 2008). There is possibility of liver damage in diabetes due to increased gluconeogenesis and ketogenesis. This disease is also grossly reflected by profound changes in protein metabolism, a negative nitrogen balance and loss of nitrogen from most organs (Mandade and Sreenivas, 2011), which might be accounted for by enhanced catabolism of both liver and plasma proteins (Ademiluyi and Oboh, 2012).

Among natural antioxidants, the olive tree has been widely accepted as one of the species with the highest antioxidant activity via its oil, fruits, and leaves. It is well known that the activity of the olive tree byproduct extracts in medicine and food industry is due to the presence of some important antioxidant and phenolic components to prevent oxidative degradations. The olive tree has long been recognized as having antioxidant molecules, such as oleuropein, hydroxytyrosol, oleuropein aglycone, and tyrosol (Jemai et al., 2008a,b). Furthermore, olive leaves are considered as a cheap raw material which can be used as a useful source of high added value products (Jemai et al., 2009). Olives are cultivated in Spain, Australia, Italy, Turkey, Greece, and other countries and olive leaves have traditionally been used for the treatment of several diseases (Del Río et al., 2003).Hence, the present study was undertaken to investigate possible antihepatotoxicity and antioxidant effects of olive leaves extracts against Streptozotocin-induced diabetic rat model.

\section{Materials and Methods}

\section{Chemicals}

All the chemicals and reagents used in this work were the highest grade available. STZ was provided by Sigma chemical company Sigma-Aldrich, USA.

\section{Olive Leaves Extract preparation}

Olive Leaves Extract (OLE) was prepared as described by [10]. Briefly, olive tree leaves were collected from Borg el-Arab region of west Alexandria. They were cleaned, dried, and grounded with a blender. $500 \mathrm{~g}$ of leaf powder were submitted to extraction with $1.5 \mathrm{~L}$ distilled water in a Soxhlet apparatus at $60^{\circ} \mathrm{C}$ for $1 \mathrm{hr}$. After extraction, the solvents were filtered and evaporated. The extract was stored at $-20^{\circ} \mathrm{C}$ until used.

\section{Experimental Animals}

The experiments were performed on male rats of Wister strain weighing (180 $\pm 20 \mathrm{~g})$. They were obtained from the central animal house, Department of Physiology, College of Medicine, Alexandria University. The rats were kept in rat cages in the laboratory for one week before the experimental work and maintained on a standard diet(7$10 \%$ fat, $68-70 \%$ carbohydrates, $18-20 \%$ protein, $1-2 \%$ vitamins and minerals; $210 \mathrm{kcal} / 100 \mathrm{~g} /$ day)and water available ad libitum . The temperature in the animal room was maintained at $\left(27 \pm 2{ }^{0} \mathrm{C}\right)$ with a relative humidity (55 \pm $5 \%$ ), light was on 12/12 h light /dark cycle. The rats were randomly and equal divided into four groups (10 rats each):

Group1 (G1): Rats of this group received Na citrate buffer. They were given standard animal pellet and water ad libitum and consider as control.

Group2 (G2): In which, rats received Olive leaves extract $0.5 \mathrm{mg} / \mathrm{kg}$ of body weight/day by oro-gastric tube for four weeks (Wainstein et al., 2012).

Group3 (G3): Rats of this group were received a single dose of streptozotocin (45mg $/ \mathrm{kg}$ of body weight) after an overnight fast to induce diabetes. Surviving rats after 3 days with blood glucose concentration more than $200 \mathrm{mg} / \mathrm{dl}$ of blood were considered as chemical-induced diabetic rats (Yadav et al., 2014).

Group4 (G4): Rats of this group were received a single dose of streptozotocin (45mg $/ \mathrm{kg}$ of body weight) and after 7 days received Olive leaves extract $(0.5 \mathrm{mg} / \mathrm{kg}$ of body weight/day) by oro-gastric tube for four weeks.

Biochemical assays

At the end of the experiment period, all animals were sacrificed and blood samples were collected from each rat in heparinized glass tube to obtain plasma. Another part of blood were collected in dry, clean and labeled tubes and allowed to coagulate in an incubator at $37^{\circ} \mathrm{C}$ for 30 minutes then they centrifuged at $3000 \mathrm{rpm}$ for 15 minutes to obtain serum, the collected plasma and serum were stored until analysis.Glucose concentration in serum was assayed by using commercial kit that was supplied by Dialab, from Austria. Glucose was estimated according to the method of (Barham and Trinder, 1972). AST and ALT activity in serum was assayed kinetically using commercial kits supplied by Spectrum Company, Germany, according to the method of Rej et al., (1975).

Cholesterol analysis was completed by measuring cholesterol ester and free cholesterol together using a test kit that was supplied by (Sigma, MO, U.S.A).Cholesterol was determined by the method of cholesterol oxidase peroxidase (CHOD-PAP) test (Allain et al., 1974). The HDL Cholesterol (HDL-C) was estimated by commercial kit that was supplied by Bio systems, from Spain, according to the method of Grove, (1979). LDL, one of lipoproteins which transport the cholesterol from liver to peripheral tissues, was calculated with reasonable accuracy by the Friedewald et al.(1972). 
The Malondialdehyde (MDA) was estimated by commercial kit that was supplied by Biodiagnostic, Egypt According to the method of (Yagi, 1998).Superoxide dismutase activity was determined in the sample using Randox superoxide dismutase kit from UK according to the method of Wooliams et al. (Woolliams et al., 1983).Catalase was measured using Bio Vision Catalase Activity Assay Kit from USA according to the method of Aebi et al (1974).

Histological examination

After scarification of rats, liver and pancreas were quickly removed and after the removal of the surrounding connective tissues carefully and then placed in saline. Then tissues were fixed in a $10 \%$ neutral-buffered formalin solution overnight. After automated dehydration through a graded alcohol and xylene series, transverse tissues slices were embedded in paraffin, sectioned at $5 \mu \mathrm{m}$ thickness The histopathology was carried out according to (Bancroft and Cook, 1994) using Harris Hematoxylin and eosin staining technique.

\section{Immunohistochemical procedure for $\beta$-cell}

The pancreatic tissues were fixed in $10 \%$ neutral buffered formalin, embedded in paraffin and sectioned at $5 \mathrm{ml}$ thickness. Immunocytochemical reaction was performed according to the Avidine Biotine technique described by Hsu et al. (1981) . The intensity of insulin in $\beta$-cells in pancreatic Islets was calculated by Quantification of immunohistochemistry staining (the antiinsulin Antibody) using Image J software.

\section{Statistical Analysis}

The mean value of rats in each group was calculated and Data were presented as arithmetic mean \pm standard Error calculated. One-way analysis of variance follwed by posthoc test was used to determine the differences between groups. Statistical analysis for obtained results was carried out with the aid of the SPSS23 computer software program. The statistical significance was defined as $\mathrm{P}<0.05$.

\section{Results}

\section{A. Effect of OLE on blood glucose and liver function enzymes in diabetic rats.}

As shown in Fig (1), blood glucose level of animals treating with OLE showed non-significant difference in serum glucose level when compared with control group. On the other hand diabetic rats showed significant increase in blood glucose levels with respect to the control. STZ +OLE group show a significant decrease in blood glucose level in comparison with diabetic group. The data in Figs (2\&3) showed that treating animals with OLE induced nonsignificant difference in serum AST, ALT activity when compared with control group over the whole experimental period. On the other hand, diabetic animals revealed a significant increase in serum AST, ALT activity. Diabetic animals treated with OLE showed a significant decrease in enzyme activity in comparison with diabetic group.

\section{B. The lipid profile biochemistry}

STZ administration was associated with a highly significant increase in cholesterol, triglyceride and LDL level as compared to the control group. On the other hand, HDL recording a significant decrease in diabetic animals as compared with the control group. Diabetic animals treated with OLE showed a significant increase as compared to STZ- group. Treating animals with OLE only showed nonsignificant difference when compared with control group (Table1).

\section{Change in MDA concentration and antioxidant enzymes:}

The concentration of lipid peroxidation end product (MDA) in blood was determined as an indicator of free radical mediated damage in tissue. MDA recoded a significant increase in STZ-group as compared with the control group. Administration of OLE together with STZ partially modulated these increased level giving a significant decrease as compared with STZ group. (Table 2). A significant decrease was observed in SOD and CAT level in rats treated with STZ in compare with the control group. OLE treatments in combination with STZ improve this decrease in SOD and CAT, giving a highly significant increase in compare with the STZ group (Table 2).

\section{Histological observations}

a.The liver

Figure (4A) showed the histological structure of the liver of control rat. The structural unit of the liver is the hepatic lobule which is made up of radiating strands, cord or plates of cells forming a network around a central vein. The hepatocytes are polyhedral in shape with a relatively large sizes and a noticeable granular cytoplasm. the liver strands are alternating with narrow blood Sinusoids also radially extending along the liver lobules,converging inwards to form the central or Centro-lobular vein. Animals administered with OLE daily for four weeks showed the same histological observations as in the liver of control animals Microscopic examination of liver sections taken from rat of STZ-group has display apparent signs of degenerative change. In these specimens, severe damages were observed in the liver architecture; the normal arrangement of the hepatocytes wasn't easily recognized and some hepatic strands were dissociated .In addition, central veins were congested (Fig.4B) Leucocytic infiltration and cytoplasmic vacuolation of the hepatocytes with pyknotic nuclei were observed (Fig.4C). Bile duct proliferation was abundant (Fig.4D). Examination of liver sections obtained from Animals treated with STZ and OLE revealed less prominent histopathological change when compared with specimen obtained from Animals treated with STZ alone. The OLE recovered the most abnormal injuries caused by DM (Fig.4 D).

\section{b.The pancreas}

Histological examination of the pancreatic tissues revealed that the pancreas of the control rats showed normal islets and acini (Fig. 5A). The architecture of the pancreas of rats treated with OLE was similar to that of the 


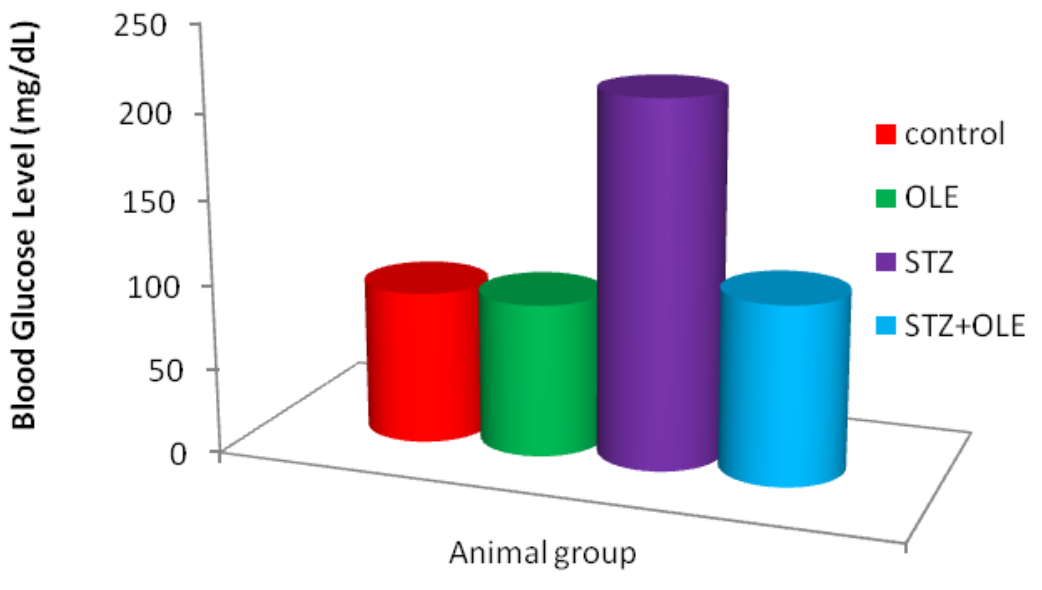

Fig.1. Effect of different treatments on glucose level.

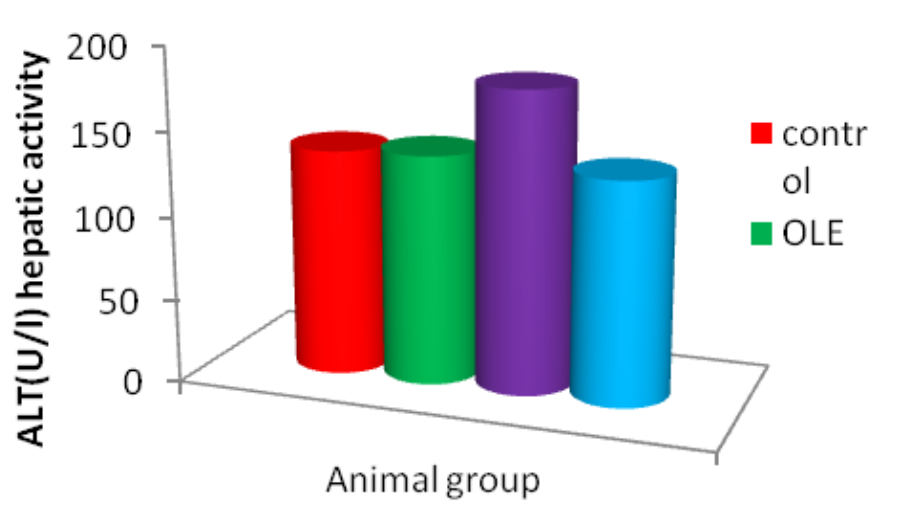

Fig.2. Effect of different treatments on ALT.

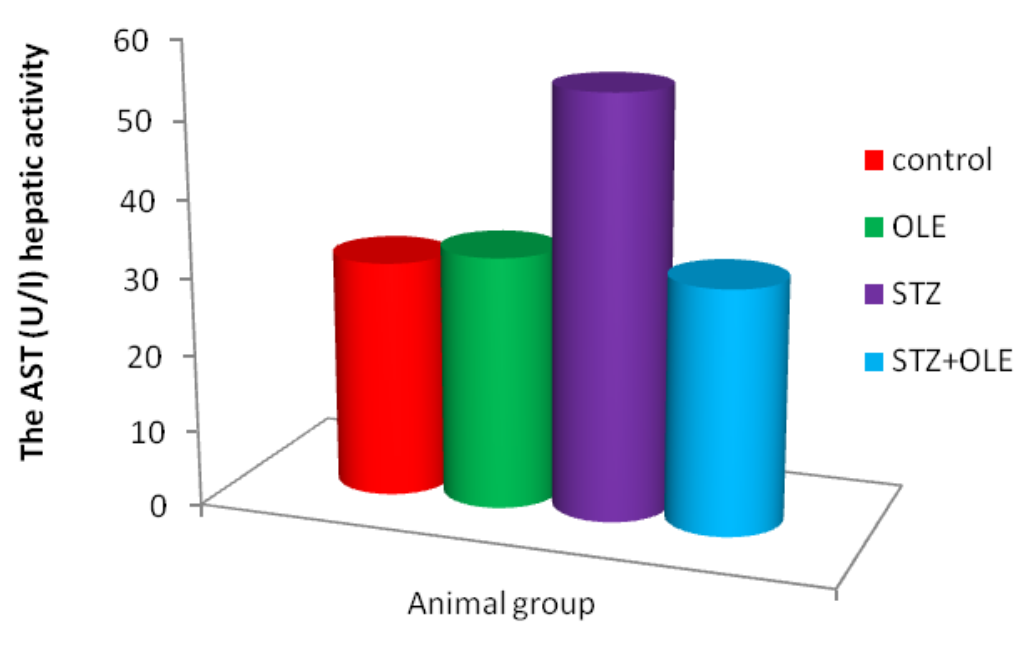

Fig.3. Effect of different treatments on AST. 
Table (1). The lipid profile (Cholesterol, Triglycerides, HDL and LDL) in different experimental animals groups

\begin{tabular}{|l|c|c|c|c|}
\hline \multicolumn{1}{|c|}{ Lipid profile } & Control & OLE & STZ & STZ+OLE \\
\hline $\begin{array}{l}\text { Cholesterol } \\
\mathbf{m g} / \mathbf{d l}\end{array}$ & $81.33^{\mathrm{b}} \pm 2.38$ & $69.83^{\mathrm{b}}+1.96$ & $142.83^{\mathrm{a}}+9.78$ & $85.33^{\mathrm{b}}+2.48$ \\
\hline $\begin{array}{l}\text { Triglycerides } \\
\mathbf{m g} / \mathbf{d l}\end{array}$ & $46.50^{\mathrm{b}} \pm 3.73$ & $31.50^{\mathrm{b}}+2.30$ & $117.67^{\mathrm{a}}+5.58$ & $83.17^{\mathrm{ab}}+3.68$ \\
\hline $\begin{array}{l}\mathbf{H D L} \\
\mathbf{m g} / \mathbf{d l}\end{array}$ & $65.00^{\mathrm{b}} \pm 2.38$ & $56.50+1.57$ & $49.83^{\mathrm{a}}+0.60$ & $57.50+5.09$ \\
\hline $\begin{array}{l}\mathbf{L D L} \\
\mathbf{m g} / \mathbf{d l}\end{array}$ & $9.90^{\mathrm{b}} \pm 1.62$ & $7.03^{\mathrm{b}}+.2 .92$ & $69.47^{\mathrm{a}}+10.33$ & $15.60^{\mathrm{b}}+4.93$ \\
\hline
\end{tabular}

- The data were expressed as mean \pm S.E.M.

- a : significantly different from the control group.

- b :significantly different from the STZ group at $\mathrm{P}<0.05$

Table (2). The change in (MDA, SOD \& CAT) levels in different experimental animals groups

\begin{tabular}{|l|c|c|c|c|}
\hline \multicolumn{1}{|c|}{ Parameter } & Control & OLE & STZ & STZ+OLE \\
\hline $\begin{array}{l}\text { MDA } \\
(\text { nmol /g protein })\end{array}$ & $8.14^{\mathrm{b}} \pm .64$ & $6.32^{\mathrm{b}} \pm .51$ & $15.11^{\mathrm{a}} \pm 1.15$ & $10.16^{\mathrm{b}} \pm .43$ \\
\hline $\begin{array}{l}\text { SOD } \\
(\mathbf{U} / \mathbf{m l})\end{array}$ & $81.07^{\mathrm{b}} \pm 15.12$ & $135.80^{\mathrm{a} b} \pm 6.21$ & $58.02^{\mathrm{a}} \pm 4.96$ & $163.70^{\mathrm{ab}} \pm 9.05$ \\
\hline $\begin{array}{l}\text { CAT } \\
(\mathbf{m} \text { mole } / \mathbf{m i n} / \mathbf{g})\end{array}$ & $51.17^{\mathrm{b}} \pm 3.04$ & $59.67^{\mathrm{b}} \pm 1.56$ & $40.17^{\mathrm{a}} \pm 2.51$ & $47.50 \pm 4.44$ \\
\hline
\end{tabular}

- $\quad$ Data are expressed as mean \pm S.E.M.

- a: Significantly different from control Group

- $\quad$ b: Significantly different vs. STZ- Group at $\mathrm{p} \leq 0.05$

control rats (Fig. 5B). Examination of pancreas sections obtained from diabetic rats, showed severe damages in the pancreas architecture. The blood vessels were congested and the acini were degenerated and their cells were swollen. Leucocytic infiltration was observed. The most consistent findings were atrophy of $\beta$ cells (Fig.5C). A clear ameliorative effect was observed in the pancreas of the diabetic rats after OLE administration. The majority of cells showed significantly improvement and the islets of Langerhans were distinctly increased in number (Fig.5D).

\section{E.Immunohistochemical observations}

The Immunohistochemical labeling of the pancreatic tissues of the control rats, and rats treated with OLE revealed a strong insulin immunopositivity in the $\beta$ cells of the islets (Figs. 6A,B). The cells of the diabetic rats, on the other hand, were essentially weak positive for insulin immunoreactivity, suggests an STZinduced targeting and destruction of insulin producing beta cells (Fig. 6C). The findings also revealed that, when compared to the diabetic rats, the diabetic rats that received OLE treatment underwent a notable increase in the number of insulin-immunoreactive $\beta$ cells and immunopositive granules (Fig. 6D). Number of $\beta$ cells was quantified as depicted in Figure 7. STZ induced a significant decrease in the intensity of insulin immunoreactive $\beta$-cells compared to control. OLE treatment resulted in increased intensity of insulin immunoreactive $\beta$-cells significantly compared to diabetic group. 

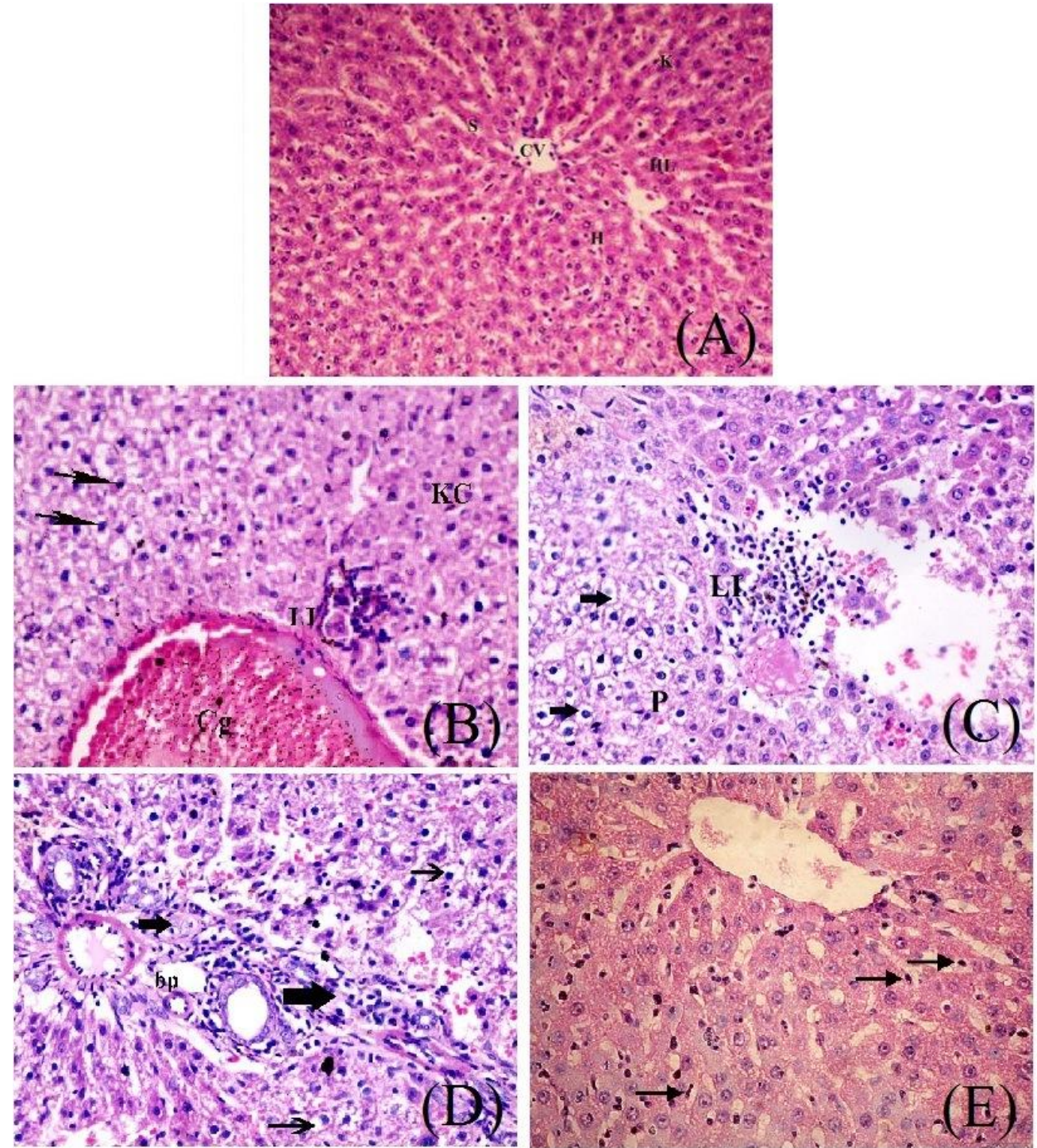

Fig.4. A). Liver section of a control rat showing hepatic lobule (HL), central vein (CV), hepatocytes (H), hepatic sinusoids(S) and Kupffer cell (K), (×200).

B). Section of liver of a DM rat showing dilated central vein with congestion (Cg), leucocytic infilteration(LI) and Kupffer cells (KC) and the hepatocytes with pyknotic nuclei (arrows), ( $\times$ 400).

C). Liver section obtained from DM rat showing leucocytic infiltration (LI) cytoplasmic vacuolization of hepatocyte (arrows) with pyknotic nuclei (P), and necrotic area , $(\times 400)$.

D). Liver section obtained from DM rat showing bile duct proliferation (bp), pyknotic nuclei (arrows) and perivascular leucocytic infiltration (thick arrows), $(\times 400)$.

E). Hepatic section of DM rat treated with OLE showing nearly normal liver tissue, activation of Kupffer cells (arrows), $(\times 400)$. 

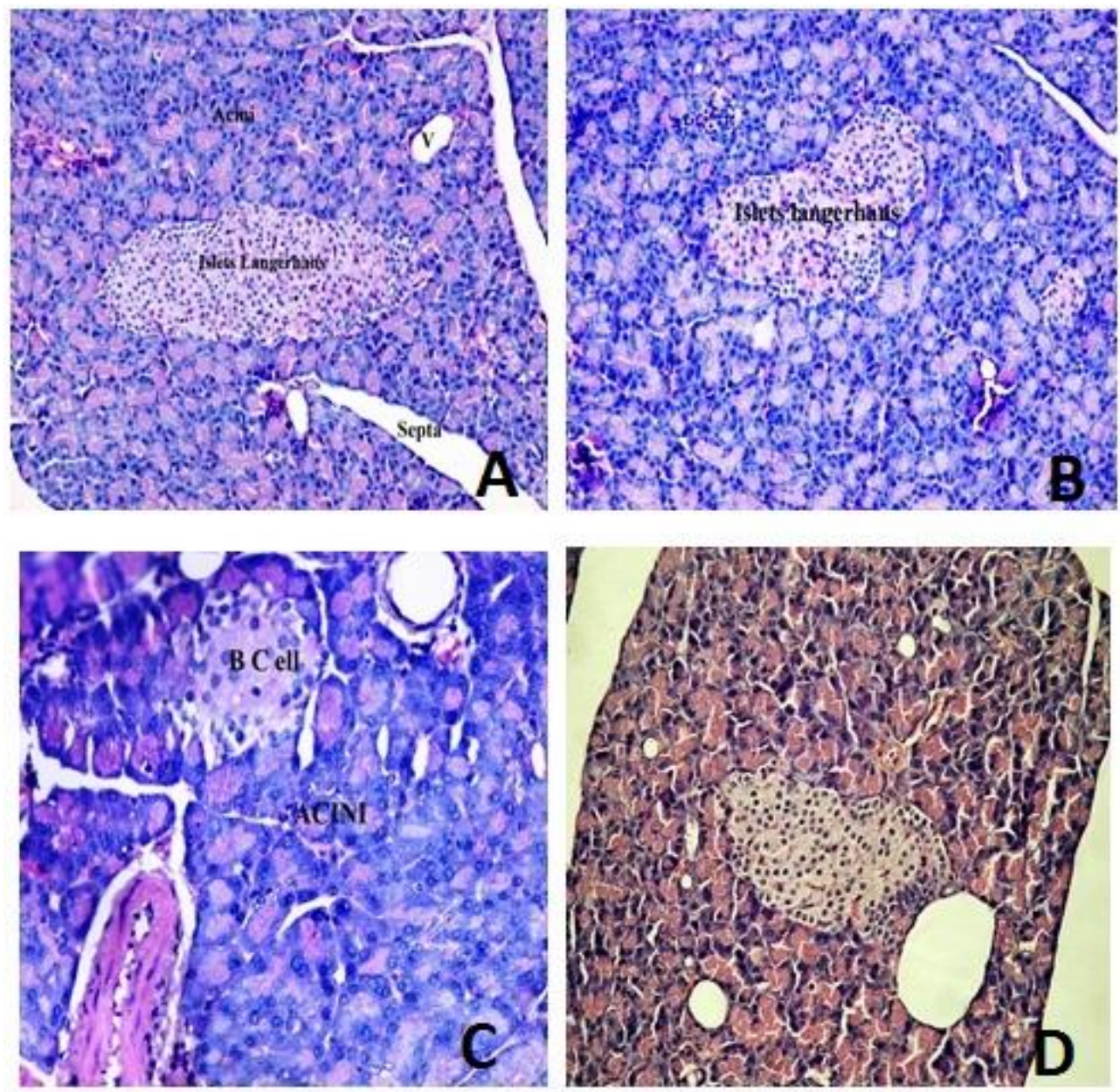

Fig.5 A). Section in a control rat showing pancreatic acini (acini) and Islets of Langerhans, normal architecture, $(H \& E \times 200)$.

B). Pancreatic section in a rat treated with OLE showing normal $\beta$ cells, acini and Islets Langerhans, (H\&E $\times 200)$.

C). Pancreatic section in DM rat showing a clear atrophy of $\beta$ cells, severe injury in Acini, (H\&E×200).

D). Pancreatic section in DM+OLE treated rat showing an improvement in acini and Islets Langerhans $(H \& E \times 200)$. 

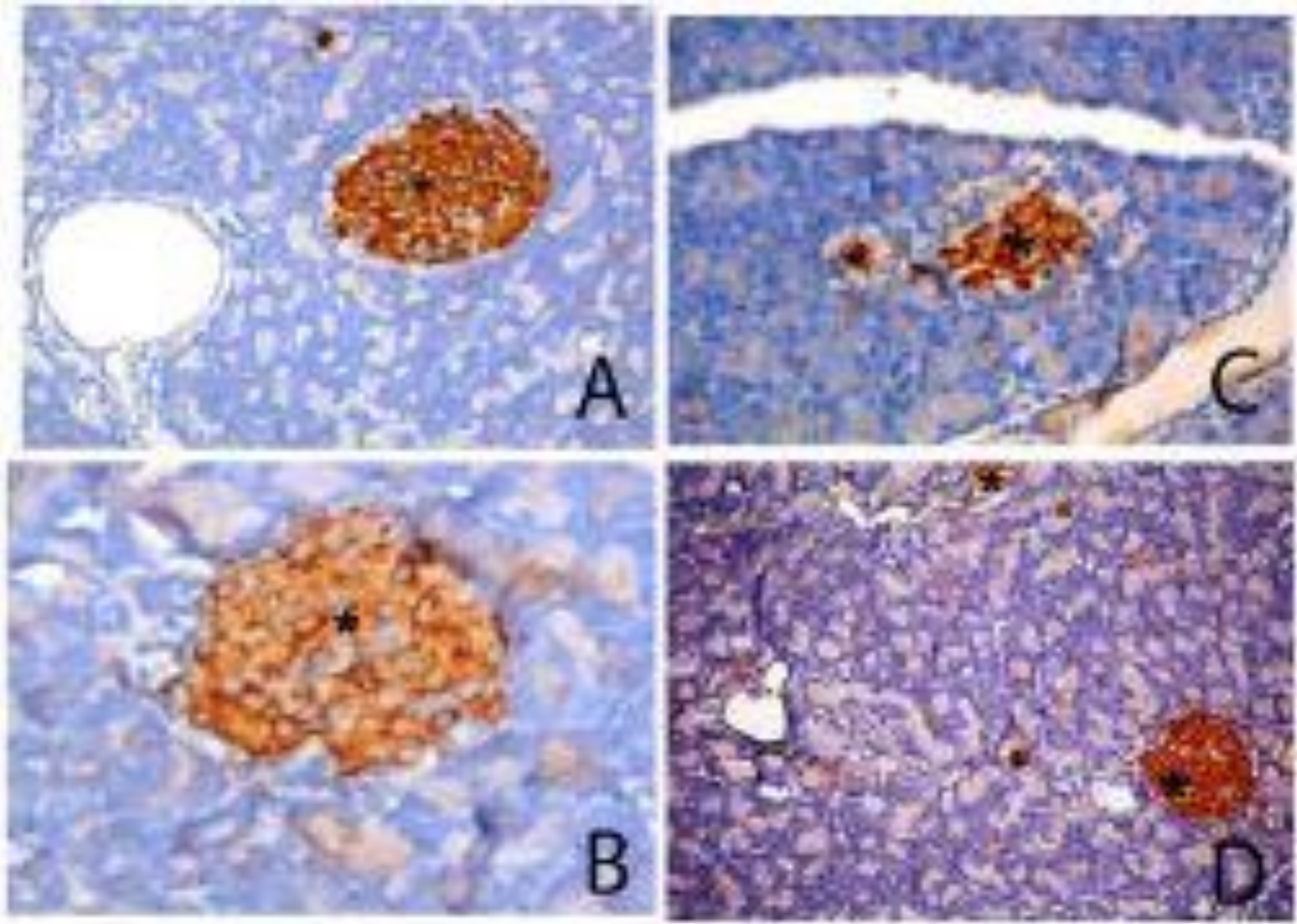

Fig.6. A). Immunohistochemical staining of the pancreatic tissues of a control rat showing: strong expression of insulin $(*)$ in the $\beta$ cells of the islets of Langerhans, $(\times 200)$.

B). Immunohistochemical labeling of the pancreatic tissues of a rat treated with OLE showing strong expression of insulin $(*)$ in the $\beta$ cells of the islets of Langerhans, $(\times 200)$.

C). Immunohistochemical staining for pancreatic insulin in a DM rat showing markedly reduction of insulin (*) in the $\beta$ cells of the islets of Langerhans, $(\times 200)$

D). Immunohistochemical labeling of the pancreatic tissues of a DM rat treated with OLE showing increase in expression of insulin $(*)$ in the $\beta$ cells of the islets of Langerhans, $(\times 200)$.

\section{Discussion}

Diabetes mellitus (DM) is a chronic debilitating condition that is rapidly increasing in prevalence worldwide, as a consequence of increases in obesity, changing patterns of diet and physical activity, and ageing populations.

Most people with diabetes live in low- and middle-income countries and these will experience the greatest increase in cases of diabetes over the next 22 years (Guariguata et al., 2014).

In the present study, the serum glucose data indicated that the administration of STZ produced significant hyperglycemic effects. This result was previously obtained by ( Rahmanian et al., 2015). Blood glucose concentration is known to depend on the ability of the liver to absorb or produce glucose. The liver performs its glucostatic function owing to its ability to synthesize or degrade glycogen according to the needs of the organism, as well as via gluconeogenesis (AlAttar and Shawush, 2014).

The obtained results showed that ALT and AST elevated in sera of diabetic animals. In accordance with these findings, Kim et al., (2012) showed that STZ treatment has a significant role in the alteration of liver functions since the activity of AST and ALT were significantly higher than those of normal values.Assessment of liver function was made by estimating the activities of serum ALT and AST which are enzymes originally present at higher concentration in the cytoplasm (Mohamed et al., 2009). When there is hepatopathy, these aminotransferases enzymes (AST and ALT) leak into the blood stream in conformity with the extent of liver damage (Nkosi et al., 2005).Although 
ALT is also present in mitochondria and cytosol, the mitochondrial form is low in activity and is very unstable. The detailed mechanism by which enzymes are released from the cytosol and mitochondria of hepatocytes is not completely known. Experimental studies have shown that subtle membrane changes are sufficient to allow passage of intracellular enzymes to the extracellular space (Fenton et al., 1997).

Moreover, the result showed that the levels of lipids (Cholesterol, Triglycerides, LDL) are raised in diabetes. Mansouri et al., (2015) reported that diabetic patients were characterized by significant increase in lipid profile and decrease of HDL (Paiva-Martins et al., 2003). Suryawanshi et al.(2006) revealed that the high levels of total cholesterol appear due to increased cholesterol synthesis, the triglyceride levels may be increased due to overproduction of LDL-TG, The same authors, reported that also insulin increases the number of LDL receptor, so chronic insulin deficiency might be associated with a diminished level of LDL receptor, this causes the increase in LDL particles and result in the increase in LDL-cholesterol value in diabetic patients.

In the present study, there was significant increase in MDA ( $\mathrm{P}<0.05)$, which was in agreement with other investigators (Jin et al., 2008; Kim et al., 2012). Increased oxidative stress is a widely accepted factor in the development and progression of diabetes and its complications. Diabetes is usually accompanied by increased production of free radicals or impaired antioxidant defenses which may give rise to increased oxidative stress (Maritim et al., 2003). Oxidative stress that leads to an increased production of ROS and finally cellular lipid peroxidation has been found to play an important role in the development of diabetes mellitus (Rajasekaran et al., 2005). Lipid peroxide-mediated tissue damage has been observed in the development of all types of diabetes mellitus ((Emekli-Alturfan et al., 2008)). Diabetes mellitus is associated with generation of ROS leading to oxidative damage particularly in liver and kidney(Jin et al., 2008).

SOD and CAT were decreased in diabetic rats. Antioxidant protective systems against ROS and the breakdown products of peroxidized lipids, oxidized protein and DNA are provided by many enzyme systems such as SOD, CAT. Oxidative stress in diabetes is coupled to a decrease in the antioxidant status, which can increase the deleterious effects of free radicals(Picton et al., 2001). SOD and CAT are the two major scavenging enzymes that remove radicals in vivo.

Treating rats with STZ caused structural alterations in the liver. These alterations include leucocytic infiltrations, congestion of blood vessels, and cytoplasmic vacuolization of hepatocytes. Similar results were also reported by some investigators in various animals subjected to different diabetic reagents (Altunkaynak et al., 2005), Also the distortion of usual arrangement of hepatic cells may be brought about by the increase in the lumen of the veins which might have pushed the surrounding cells. Similarly Safer et al., (2015) indicated that there is extensive damage to liver cells which is replaced by a fibrous tissue. Other pathological features observed were the destruction of the lobular architecture, inflammation, vacuolated cytoplasm, necrosis, nuclear karyorrhesis, nuclear karyolysis, nuclear hyperchromatism, dead cells and thickening of the portal vein. Furthermore, in the liver of diabetic rats, shrunken nuclei, granular cytoplasm, dilatation in the sinusoids and inflammation were noticed (Guven et al., 2006; Noor et al., 2008). These changes were due to Excess glycogen accumulation in the liver of diabetic patients due to defective activation of glycogen synthase. (Can et al., 2004).

STZ given to rats was found to induce damage to the acinus and pancreatic islets and the immediate action of STZ was specifically on $\beta$-cells. The present study come in accordance with those obtained by Kanter et al.( 2009) who reported that even at a smaller dose (45 $\mathrm{mg} / \mathrm{kg}$ ) the pancreatic acinar cells were damaged. Also, Das et al. (1996) reported that STZ caused degranulation of $\beta$-cell. The findings of this study have demonstrated significant changes in the number and pattern of distribution of insulin-immunopositive cells in the pancreas of diabetic rat when compared to normal rats. These finding corroborates those of previous studies on the pattern of distribution of insulin in normal and diabetic rat pancreases (Jolivalt et al., 2015).

Concerning the effect of OLE, the present results revealed that OLE ameliorated the level of glucose in diabetic rats. Similarely, oral administration of the extract from Olea europaea caused significant hypoglycemic effects only in streptozotocin-induced diabetic rats and not in normal rats (de Bock et al., 2013, Rahmanian et al., 2015). Also, the extract affected insulin release from the pancreas of the diabetic group.It was reported that the hypoglycemic activity of this OLE may result from two mechanisms:1)potentiation of glucose-induced insulin release, and 2)Increased peripheral uptake of glucose ( El Sedef \& Karakaya, 2009). Another way in which OLE might exert its hypoglycemic effect is through the inhibition of pancreatic amylase activity (Komaki et al., 2003).

The result showed that OLE exhibited a significant decrease in the level of serum lipids (Cholesterol,Triglycerides, LDL )in diabetic rats.OLE and its corresponding acid and enzymatic hydrolysate extracts were tested for their lipid-lowering activities (Cholesterol,Triglycerides,LDL) in hyper cholesterolemic rats (Jemai et al., 2008b). Phenolic compounds from various sources have been reported to prevent LDL oxidation in vitro and show marked hypolipidemic activity in vivo ( Paiva-Martins et al., 2003).

In this study, it was found that OLE treatment resulted in an obvious increase of the SOD and CAT activity, with a decrease of lipid peroxidation marker,MDA. This is in accordance with some recent 
studies, in which polyphenol enriched plant extracts effectively enhanced the SOD activity and reduced the MDA in rat (Cui et al., 2014, Mansouri et al., 2015). It was reported that olive leaf extract Olea europaea had highest radical scavenging activity (Wojcikowski et al., 2007).

OLE treatment ameliorated the histopatholoical alterations of hepatic cells observed in STZ-diabetic rats together with a reduction of ALT and AST. This is in agreement with Kumral et al., (2015).Also, OLE reversed the damage in pancreas of diabetic rats. OLE are rich in phenolic compounds including flavones, flavonols, catechin and substituted phenols (Japón-Luján et al., 2006). The most abundant polyphenol in olive leaves is oleuropein, which accounts for approximately $20 \%$ of phenolic compounds in the olive leaf, which has been shown to suppress insulin secretion in $\mathrm{H}_{2} \mathrm{O}_{2}$ exposed cells (Cumaoğlu et al., 2011). Olive leaf phenolic compounds have been shown to have both antioxidant and anti-inflammatory properties (Visioli et al., 2002, Pereira et al., 2006).

It is concluded from the obtained results that the ameliorative effect of olive leave extracts against toxicity of diabetes in rats may be attributed to the presence of its phenolic compounds.

\section{References}

Abo, K., Fred-Jaiyesimi, A., Jaiyesimi, A., 2008. Ethnobotanical studies of medicinal plants used in the management of diabetes mellitus in South Western Nigeria. Journal of Ethnopharmacology 115, 67-71.

Ademiluyi, A.O., Oboh, G., 2012. Attenuation of oxidative stress and hepatic damage by some fermented tropical legume condiment diets in streptozotocin-induced diabetes in rats. Asian Pacific journal of tropical medicine 5, 692-697.

Aebi, H., 1974. Catalases. Methods of enzymatic analysis 2, 673-684.

Aggarwal, B.B., Harikumar, K.B., 2009. Potential therapeutic effects of curcumin, the anti-inflammatory agent, against neurodegenerative, cardiovascular, pulmonary, metabolic, autoimmune and neoplastic diseases. The international journal of biochemistry \& cell biology 41, 40-59.

Al-Attar, A.M., Shawush, N.A., 2014. Physiological investigations on the effect of olive and rosemary leaves extracts in male rats exposed to thioacetamide. Saudi journal of biological sciences 21, 473-480.

Allain, C.C., Poon, L.S., Chan, C.S., Richmond, W., Fu, P.C., 1974. Enzymatic determination of total serum cholesterol. Clinical chemistry 20, 470-475.

Altunkaynak, A., Özger, M., Çakmakci, M., 2005. Water consumption prediction of Istanbul city by using fuzzy logic approach. Water Resources Management 19, 641-654.

Bancroft, J.D., Cook, H.C., 1994. Manual of histological techniques and their diagnostic application. Churchill Livingstone.
Barham, D., Trinder, P., 1972. An improved colour reagent for the determination of blood glucose by the oxidase system. Analyst 97, 142-145.

Can, A., Akev, N., Ozsoy, N., Bolkent, S., Arda, B.P., Yanardag, R., Okyar, A., 2004. Effect of Aloe vera leaf gel and pulp extracts on the liver in type-II diabetic rat models. Biological and Pharmaceutical Bulletin 27, 694698.

Cui, G., Qin, X., Zhang, Y., Gong, Z., Ge, B., Zang, Y.Q., 2009. Berberine differentially modulates the activities of ERK, p38 MAPK, and JNK to suppress Th17 and Th1 $\mathrm{T}$ cell differentiation in type 1 diabetic mice. Journal of Biological Chemistry 284, 28420-28429.

Cumaoğlu, A., L. Rackova, M. Stefek, M. Kartal, P. Maechler and C. Karasu, 2011: Effects of olive leaf polyphenols against $\mathrm{H} 2 \mathrm{O} 2$ toxicity in insulin secreting $\beta$ cells. Acta Biochim Pol, 58, 45-50.

Das, A. V., P. S. Padayatti and C. Pauiose, 1996: Effect of leaf extract of emarmelose (L.) Correa ex Roxb. on histological and ultrastructural changes in tissues of streptozotocin induced diabetic rats. Indian journal of Experimental biology, 34, 341-345.

de Bock, M., J. G. Derraik, C. M. Brennan, J. B. Biggs, P. E. Morgan, S. C. Hodgkinson, P. L. Hofman and W. S. Cutfield, 2013: Olive (Olea europaea L.) leaf polyphenols improve insulin sensitivity in middle-aged overweight men: a randomized, placebo-controlled, crossover trial. PloS one, 8, e57622.

Del Río, J., Báidez, A., Botía, J., Ortuño, A., 2003. Enhancement of phenolic compounds in olive plants (Olea europaea L.) and their influence on resistance against Phytophthora sp. Food Chemistry 83, 75-78.

Eizirik, D.L., Mandrup-Poulsen, T., 2001. A choice of death-the signal-transduction of immune-mediated betacell apoptosis. Diabetologia 44, 2115-2133.

El Sedef, N. and S. Karakaya, 2009: Olive tree (Olea europaea) leaves: potential beneficial effects on human health. Nutrition Reviews, 67, 632-638.

Emekli-Alturfan, E., Kasikci, E., Yarat, A., 2008. Peanut (Arachis hypogaea) consumption improves Glutathione and HDL-cholesterol levels in experimental diabetes. Phytotherapy Research 22, 180-184.

Fenton, S.S., Schaubel, D.E., Desmeules, M., Morrison, H.I., Mao, Y., Copleston, P., Jeffery, J.R., Kjellstrand, C.M., 1997. Hemodialysis versus peritoneal dialysis: a comparison of adjusted mortality rates. American Journal of Kidney Diseases 30, 334-342.

Friedewald, W.T., Levy, R.I., Fredrickson, D.S., 1972. Estimation of the concentration of low-density lipoprotein cholesterol in plasma, without use of the preparative ultracentrifuge. Clinical chemistry 18, 499-502.

Fu, Z., Zhen, W., Yuskavage, J., Liu, D., 2011. Epigallocatechin gallate delays the onset of type 1 diabetes in spontaneous non-obese diabetic mice. British journal of nutrition 105, 1218-1225.

Grove,T.H.,1979: Effect of reagent $\mathrm{PH}$ on determination of high-denisty lipoprotin with cholesterol by 
precipitation with sodium phosphotungstate-magnesium clinical chemistry,25,560-564.

Guariguata, L., Whiting, D., Hambleton, I., Beagley, J., Linnenkamp, U., Shaw, J., 2014. Global estimates of diabetes prevalence for 2013 and projections for 2035. Diabetes research and clinical practice 103, 137-149.

Guven, A., Yavuz, O., Cam, M., Ercan, F., Bukan, N., Comunoglu, C., Gokce, F., 2006. Effects of melatonin on streptozotocin-induced diabetic liver injury in rats. Acta histochemica 108, 85-93.

Hsu, S.-M., L. Raine and H. Fanger, 1981: Use of avidin-biotin-peroxidase complex (ABC) in immunoperoxidase techniques: a comparison between $\mathrm{ABC}$ and unlabeled antibody (PAP) procedures. Journal of Histochemistry \& Cytochemistry, 29, 577-580.

Japón-Luján, R., J. Luque-Rodríguez and M. L. De Castro, 2006: Dynamic ultrasound-assisted extraction of oleuropein and related biophenols from olive leaves. Journal of Chromatography A, 1108, 76-82.

Jemai, H., Bouaziz, M., Fki, I., El Feki, A., Sayadi, S., 2008a. Hypolipidimic and antioxidant activities of oleuropein and its hydrolysis derivative-rich extracts from Chemlali olive leaves. Chemico-biological interactions 176, 88-98.

Jemai, H., El Feki, A., Sayadi, S., 2009. Antidiabetic and antioxidant effects of hydroxytyrosol and oleuropein from olive leaves in alloxan-diabetic rats. Journal of Agricultural and Food Chemistry 57, 8798-8804.

Jemai, H., Fki, I., Bouaziz, M., Bouallagui, Z., El Feki, A., Isoda, H., Sayadi, S., 2008b. Lipid-lowering and antioxidant effects of hydroxytyrosol and its triacetylated derivative recovered from olive tree leaves in cholesterolfed rats. Journal of agricultural and food chemistry 56, 2630-2636.

Jin, L., Xue, H.-Y., Jin, L.-J., Li, S.-Y., Xu, Y.-P., 2008. Antioxidant and pancreas-protective effect of aucubin on rats with streptozotocin-induced diabetes. European journal of pharmacology 582, 162-167.

Kanter, M., M. Akpolat and C. Aktas, 2009: Protective effects of the volatile oil of Nigella sativa seeds on $\beta$-cell damage in streptozotocin-induced diabetic rats: a light and electron microscopic study. Journal of Molecular Histology, 40, 379-385.

Kim, J.-J., Thiyagarajan, R., Kim, S.-J., 2012. Protective effects of Chrysanthemi Flos extract against streptozotocin-induced oxidative damage in diabetic mice. J Med Plants Res 6, 622-630.

Kim, S.G., Choi, D.S., 2009. Epidemiology and current status of diabetes in Korea. Hanyang Medical Reviews 29, 122-129.

Komaki, E., S. YamaguchI, I. Maru, M. Kinoshita, K. Kakehi, Y. Ohta and Y. Tsukada, 2003: Identification of Anti-. ALPHA.-Amylase Components from Olive Leaf Extracts. Food Science and Technology Research, 9, 35-39.

Kumral, A., M. Soluk-Tekkeşin, V. Olgaç, S. DoğruAbbasoğlu, Ü. Türkoğlu and M. Uysal, 2015: Effect of olive leaf extract treatment on doxorubicin-induced cardiac, hepatic and renal toxicity in rats. Pathophysiology, 22, 117123.

Leclercq, I.A., Morais, A.D.S., Schroyen, B., Van Hul, N., Geerts, A., 2007. Insulin resistance in hepatocytes and sinusoidal liver cells: mechanisms and consequences. Journal of hepatology 47, 142-156.

Mandade, R., Sreenivas, Z., 2011. Anti-Diabetic Effects of Aqueous Ethanolic Extract ofHibiscus rosasinensis L. on Streptozotocin-Induced Diabetic Rats and the Possible Morphologic Changes in the Liver and Kidney. International Journal of Pharmacology 7, 363-369.

Mansouri, E., Khorsandi, L., Moaiedi, M.Z., 2015. Grape Seed Proanthocyanidin Extract Improved some of Biochemical Parameters and Antioxidant Disturbances of Red Blood Cells in Diabetic Rats. Iranian journal of pharmaceutical research: IJPR 14, 329.

Maritim, A., Sanders, R., Watkins, r.J., 2003. Diabetes, oxidative stress, and antioxidants: a review. J Biochem Mol Toxicol 17.

Nakhjavani, M., Morteza, A., Nargesi, A.A., Mostafavi, E., Esteghamati, A., 2013. Appearance of leptin-HSP70 correlation, in type 2 diabetes. Meta gene 1, $1-7$.

Nkosi, C., Opoku, A., Terblanche, S., 2005. Effect of pumpkin seed (Cucurbita pepo) protein isolate on the activity levels of certain plasma enzymes in CCl4-induced liver injury in low-protein fed rats. Phytotherapy research 19, 341-345.

Noor, A., Gunasekaran, S., Soosai Manickam, A., Vijayalakshmi, M., 2008. Antidiabetic activity of Aloe vera and histology of organs in streptozotocin-induced diabetic rats. Current science 94, 1070-1076.

olivalt, C. G., M. Rodriguez, J. Wahren and N. A. Calcutt, 2015: Efficacy of a long-acting C-peptide analogue against peripheral neuropathy in streptozotocin-diabetic mice. Diabetes, Obesity and Metabolism,8,781-788.

Paiva-Martins, F., Gordon, M.H., Gameiro, P., 2003. Activity and location of olive oil phenolic antioxidants in liposomes. Chemistry and physics of lipids 124, 23-36.

Pereira, J. A., A. P. Pereira, I. C. Ferreira, P. Valentão, P. B. Andrade, R. Seabra, L. Estevinho and A. Bento, 2006: Table olives from Portugal: phenolic compounds, antioxidant potential, and antimicrobial activity. Journal of Agricultural and Food Chemistry, 54, 8425-8431.

Picton, S.F., Flatt, P.R., McCLENAGHAN, N.H., 2001. Differential acute and long term actions of succinic acid monomethyl ester exposure on insulin-secreting BRIN-BD11 cells. Journal of Diabetes Research 2, 19-27.

Rahmanian, N., Jafari, S.M., Wani, T.A., 2015. Bioactive profile, dehydration, extraction and application of the bioactive components of olive leaves. Trends in Food Science \& Technology 42, 150-172.

Rajasekaran, S., Sivagnanam, K., Subramanian, S., 2005. Antioxidant effect of Aloe vera gel extract in streptozotocin-induced diabetes in rats. Pharmacol Rep 57, 90-96. 
Raptis, A., Viberti, G., 2000. Pathogenesis of diabetic nephropathy. Experimental and clinical endocrinology \& diabetes: official journal, German Society of Endocrinology and German Diabetes Association 109, S424-437.

Rej, R., Fasce, C., Vanderlinde, R.E., 1975. Interlaboratory proficiency, intermethod comparison, and calibrator suitability in assay of serum aspartate aminotransferase activity. Clinical chemistry 21, 11411158.

Ren, X.-Y., Li, Y.-N., Qi, J.-S., Niu, T., 2008. Peroxynitrite-induced protein nitration contributes to liver mitochondrial damage in diabetic rats. Journal of Diabetes and its Complications 22, 357-364.

Safer, A.-M., Afzal, M., Hanafy, N., Mousa, S., 2015. Green tea extract therapy diminishes hepatic fibrosis mediated by dual exposure to carbon tetrachloride and ethanol: A histopathological study. Experimental and therapeutic medicine 9, 787-794.

Seddik, L., Bah, T., Aoues, A., Brnderdour, M., Silmani, M., 2010. Dried leaf extract protects against leadinduced neurotoxicity in Wistar rats. Eur J Sci Res 42, 139151.

Suryawanshi, N., Bhutey, A., Nagdeote, A., Jadhav, A., Manoorkar, G., 2006. Study of lipid peroxide and lipid profile in diabetes mellitus. Indian journal of clinical Biochemistry 21, 126-130.

Tesfaye, S., Selvarajah, D., 2012. Advances in the epidemiology, pathogenesis and management of diabetic peripheral neuropathy. Diabetes/metabolism research and reviews 28, 8-14.
Visioli, F., A. Poli and C. Gall, 2002: Antioxidant and other biological activities of phenols from olives and olive oil. Medicinal research reviews, 22, 65-75.

Wainstein, J., Ganz, T., Boaz, M., Bar Dayan, Y., Dolev, E., Kerem, Z., Madar, Z., 2012. Olive leaf extract as a hypoglycemic agent in both human diabetic subjects and in rats. Journal of medicinal food 15, 605-610.

Wojcikowski, K., L. Stevenson, D. Leach, H. Wohlmuth and G. Gobe, 2007: Antioxidant capacity of 55 medicinal herbs traditionally used to treat the urinary system: a comparison using a sequential three-solvent extraction process. The Journal of Alternative and Complementary Medicine, 13, 103-110.

Woolliams, J., Wiener, G., Anderson, P., McMurray, C., 1983. Variation in the activities of glutathione peroxidase and superoxide dismutase and in the concentration of copper in the blood in various breed crosses of sheep. Research in veterinary science 34, 253256.

Yadav, S.K., Nagori, B.P., Desai, P.K., 2014. Pharmacological characterization of different fractions of Calotropis procera, Asclepiadaceae in streptozotocin induced experimental model of diabetic neuropathy. Journal of ethnopharmacology 152, 349-357.

Yagi, K., 1998. Simple assay for the level of total lipid peroxides in serum or plasma, Free radical and antioxidant protocols. Springer, pp. 101-106. 